\title{
Equipamento
}

\section{para protecção pessoal}

A consciencialização para a segurança e prevenção de acidentes deve ser parte integrante do treino de todas as pessoas que trabalham em laboratórios.

Os perigos potenciais do trabalho laboratorial resultam do manuseamento de materiais nocivos (inflamáveis, explosivos, corrosivos, tóxicos, radioactivos, etc.), de equipamento eléctrico e com partes móveis, de material de vidro danificado e de instrumentos de corte, gases comprimidos, fluidos criogénicos, radiação ultravioleta, raios $\mathrm{X}$, lasers, agentes patogénicos, entre outros. Praticamente todos os acidentes podem ser evitados desde que todas as pessoas que trabalham em laboratórios cumpram um código de conduta pessoal e obedeçam a algumas regras simples em todas as ocasiðes. A primeira dessas regras diz respeito ao uso de roupa protectora e outro equipamento para protecção pessoal no local de trabalho.

\section{1 - Protecção do corpo e do vestuário}

Existe uma grande variedade de vestuário protector contra derrames químicos, calor, frio, humidade, radiaçð̃es, etc. Basicamente, o vestuário protector deve ser resistente a acidentes de natureza física e permitir a execução fácil, e com conforto, das tarefas manuais, ao mesmo tempo que deve cumprir certo número de requisitos determinados pelo trabalho a executar. A seleç̧ão do tipo de vestuário deve, pois, ser adequadamente planeada e para tal, além da informação contida em catálogos comerciais, deverá ser consultada bibiografia sobre o assunto, de que é exemplo a obra de A.D. Little, intitulada Guidelines for the Selection of Chemical Protective Clothing, publicada em 1983 sob os auspícios da Environmental Protection Agency, nos E.U.A.

Para segurança do trabalhador, é importante que no laboratório não use roupa muito larga e solta (por exemplo, saris, gravatas, lenços de pescoço, batas largas) ou rasgada, nem cabelos compridos soltos, pois podem prender-se em equipamentos ou máquinas em movimento, mergulhar em produtos químicos ou pegar fogo.

Para protecção do corpo e do vestuário, é imprescindível o uso de batas, de preferência de algodão, já que muitas fibras sintéticas podem gerar electricidade estática por friç̧ão, tornando-se o seu uso perigoso em zonas de baixa humidade em que haja perigo de incêndio.

Contudo, as batas destinam-se essencialmente à protecção do vestuário, podendo mesmo envolver certos perigos, por exemplo combustibilidade e resistência pouco significativa à penetração por líquidos orgânicos.

Os aventais de plástico ou de borracha oferecem melhor protecção contra líquidos corrosivos ou irritantes, mas em caso de incêndio podem vir a causar complicaçðes

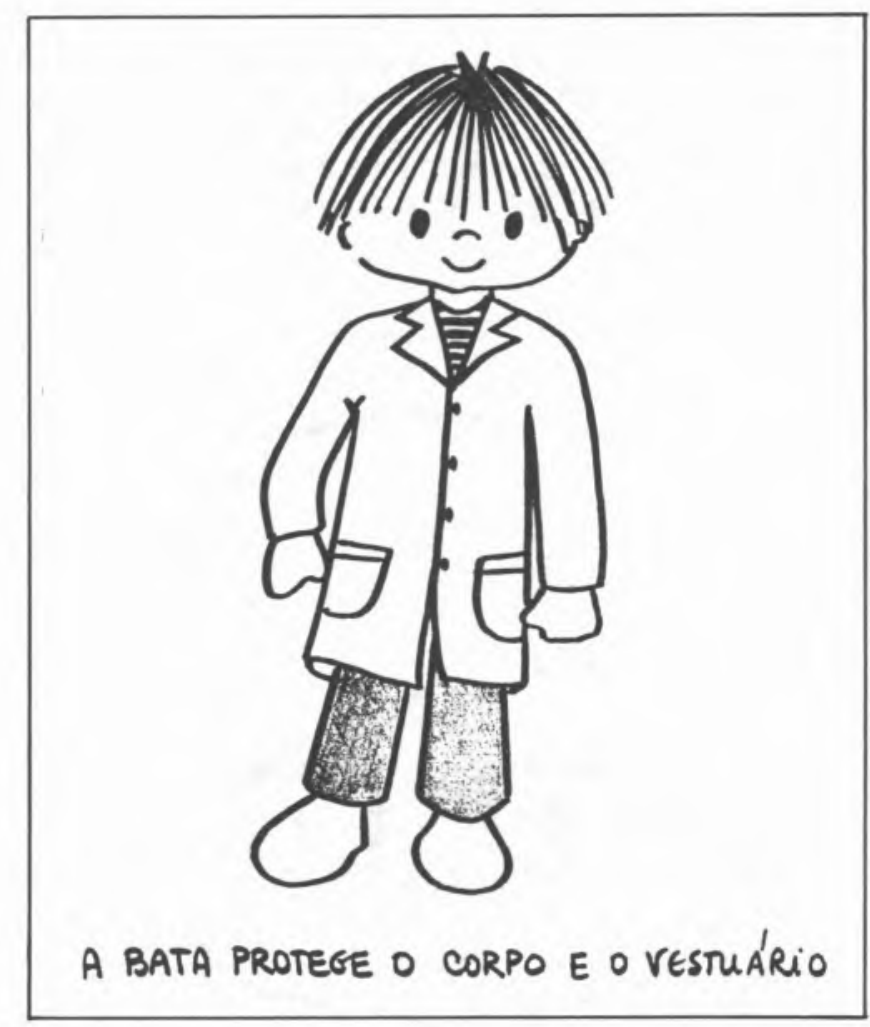

nas lesð̃es eventualmente sofridas. Os aventais de plástico podem acumular uma carga considerável de electricidade estática, pelo que não devem ser usados em áreas em que haja possibilidade de ignição de solventes inflamáveis por descargas estáticas.

Em certos casos, é preferível o uso de vestuário protector de usar e deitar fora (por exemplo, em Tyvek), como é o caso do manuseamento de substâncias cancerígenas.

Para situaçðes de alto risco, devem ser usados fatos-macaco de usar e deitar fora, podendo ser igualmente requerida protecção para a cabeça e sapatos. No entanto, este tipo de vestuário é pouco resistente à penetração de vapores.

Todas as pessoas que trabalham no laboratório devem conhecer as técnicas apropriadas para remoção de roupa protectora, particularmente quando se encontra contaminada. Os derrames químicos em vestuário ou acessórios de pele (correias de relógio, cintos, sapatos, etc.) são extremamente perigosos, pois muitos produtos químicos são absorvidos pelo cabedal e podem por isso manter-se em contacto com a pele por períodos prolon-

a Departamento de Tecnologia de Indústria Quimica (LNETI), Estrada das Palmeiras, 2745, Queluz. 
gados; em tais casos, esses artigos devem ser removidos e descontaminados ou eliminados, para evitar a possibilidade de ocorrência de queimaduras químicas.

Para utilização em caso de contaminação grave do vestuário ou da pele, em especial no caso de derrames químicos, devem existir no laboratório chuveiros de emergência.

\section{2 - Protecção dos olhos e da face}

A protecção dos olhos é da máxima importância e todas as pessoas devem usar sempre óculos de segurança no laboratório. Não deve ser permitida a circulação de visitantes nos laboratórios se não estiverem equipados com óculos de segurança.

Os óculos normais não oferecem protecção adequada, requerendo-se no laboratório o uso de óculos com lentes de plástico ou de vidro endurecido (que poderão ser graduados de acordo com a prescrição do médico para cada indivíduo) com um mínimo de $3 \mathrm{~mm}$ de espessura, resistentes ao impacto, testados quanto à flamabilidade e com armação capaz de suster as lentes em condiçðes de trabalho laboratorial.

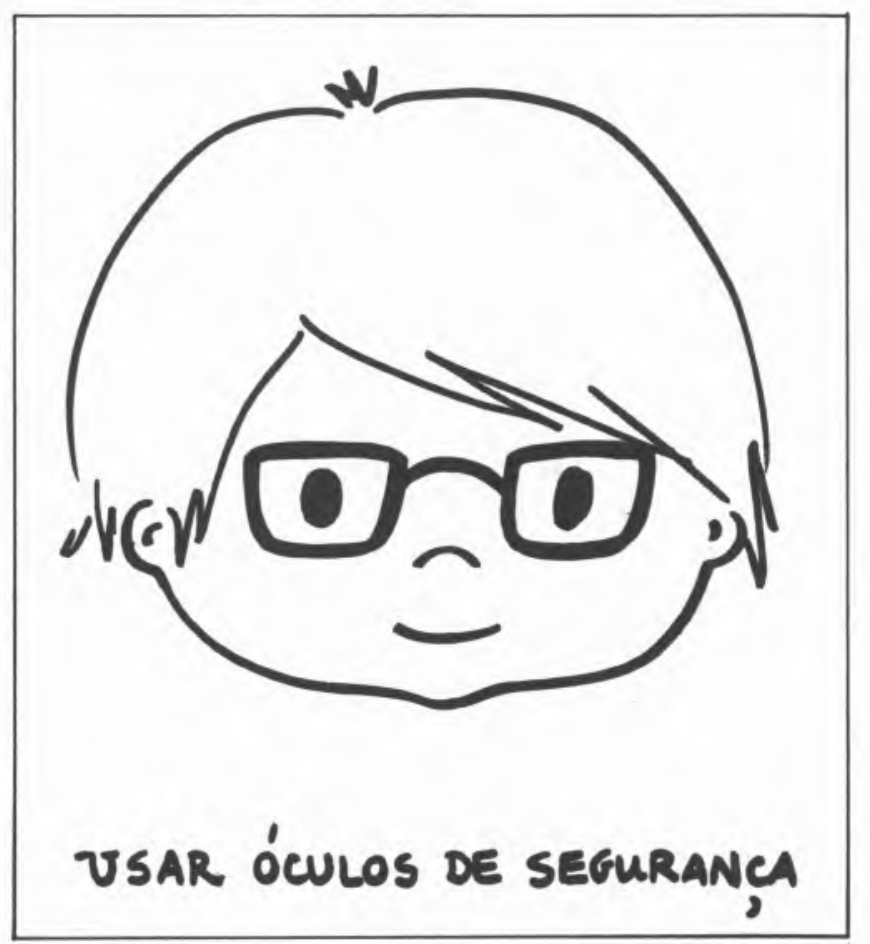

Os b́culos de segurança oferecem protecção adequada para a maior parte do trabalho de rotina de um laboratório. Contudo, há casos em que pode ser necessária uma protecção mais completa; os óculos de segurança com protecçð̃es laterais protegem de objectos que se aproximem lateralmente do seu utilizador, mas não quando haja possibilidade de ocorrência de salpicos químicos, caso em que é preferível optar por viseiras faciais, que oferecem boa protecção para os olhos, face e garganta. Todos os trabalhos que envolvam risco de explosão ou de implosão devem ser efectuados por trás de écrans de segurança, e dentro de uma hote. Para protecção do operador, é importante o dimensionamento correcto das hotes, para que o trabalho possa ser executado sem que o operador tenha necessidade de introduzir a cabeça dentro da hote.

As lentes dos óculos de segurança, as viseiras e os écrans de segurança deverão ser mantidos limpos e sem riscos, pois caso contrário podem obscurecer a visão e provocar cansaço da vista.

As lentes de contacto não substituem os óculos de segurança e não devem ser usadas no laboratório. Um deslocamento súbito das lentes pode causar problemas visuais momentâneos, impedindo o operador de prestar a vigilância constante requerida pela maioria dos trabalhos laboratoriais. Os gases ou vapores que se concentram sob as lentes de contacto podem provocar lesð̄es permanentes da vista, além de que, quando corpos estranhos se alojam na vista, as lentes de contacto tendem a evitar que os fluidos naturais removam os contaminantes sólidos ou líquidos; por outro lado, a remoção das lentes de contacto, quando se introduz algum corpo estranho, é difícil devido a espasmos involuntários das pálpebras. As lentes de contacto não-rígidas podem absorver vapores de solventes, mesmo através de viseiras, e, como resultado, aderir ao globo ocular.

No laboratório deverão existir esguichos apropriados para a lavagem dos olhos, contendo água destilada, e/ou chuveiros para lavagem dos olhos, de que existem modelos adaptáveis às próprias torneiras do laboratório.

\section{3 - Proteç̧ão da pele e das mãos}

Nos laboratórios existem numerosas substâncias que podem causar irritação da pele e originar dermatites pelo que se deve utilizar luvas, não só para evitar o contacto da pele com líquidos e sólidos, mas também para evitar outros acidentes como queimaduras, cortes, etc. Existem muitos tipos de luvas apropriados para as diferentes tarefas inerentes ao trabalho laboratorial; as luvas de algodão ou de cabedal protegem as mãos de abrasivos, objectos aguçados e com arestas cortantes; as luvas de borracha natural ou sintética podem ser utilizadas no manuseamento de solventes, ácidos concentrados e outras substâncias corrosivas, mas dado que a sua

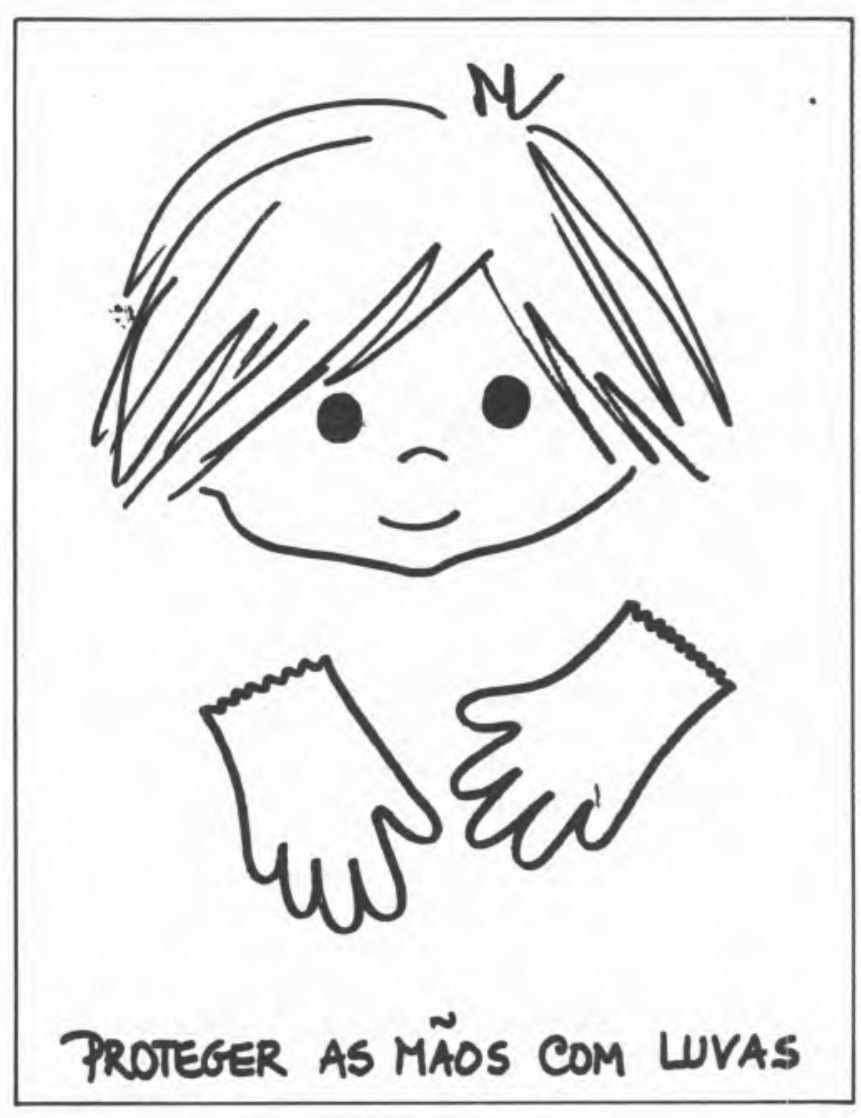


resistência à acção de vários agentes químicos é diferente consoante o material de que são fabricadas, deverão consultar-se a bibliografia e catálogos comerciais para proceder à seleção do material mais adequado às tarefas a realizar. Para além da selecção apropriada das luvas, estas devem ser inspeccionadas periodicamente, para detectar descoloração, perfuraçð̃es e cortes; antes de remover as luvas, estas devem ser lavadas e deve proceder-se à sua substituição periódica. No manuseamento de fluidos criogénicos deve recorrer-se a luvas de cano alto, para evitar a entrada de fluidos nas luvas, o que pode provocar queimaduras graves na pele. Não é aconselhável o uso de luvas próximo de equipamentos com partes móveis.

Para protecção da pele e das mãos é muito importante a limpeza pessoal. A remoção da pele de contaminantes com solventes orgânicos é prejudical pois não só seca a pele, tornando-a mais vulnerável, como pode facilitar a absorção desses contaminantes através da pele. A água e o sabão são os produtos de limpeza recomendados.

Não se deve usar anéis no laboratório, pois podem reagir com produtos químicos ou prenderem-se em equipamentos com partes móveis.

Existem cremes protectores para as mãos (barrier creams) de vários tipos, que deverão ser seleccionados e utilizados de acordo com as instruções do fabricante e tendo presente o facto de que só oferecem uma protecção parcial.

\section{4 - Protecção das vias respiratórias}

A existência no laboratório de um bom sistema de ventilação e de hotes com boa tiragem são os factores básicos para a protecção das vias respiratórias de todos os trabalhadores do laboratório.

Contudo, trabalhos que envolvem o manuseamento de poeiras, vapores e gases tóxicos ou irritantes requerem protecção adicional para as vias respiratórias.

Assim, em todos os laboratórios devem existir máscaras respiratórias com filtros.

A escolha da máscara respiratória e dos filtros depende do tipo de trabalho a que se destinam, do contaminante e estimativa da sua concentração no local, limites de

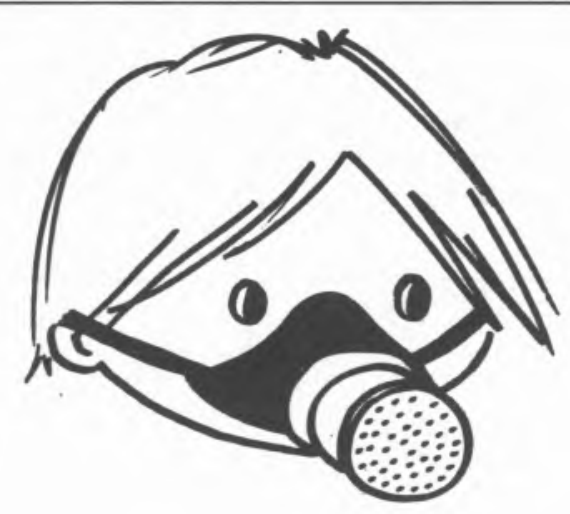

NO TRABALHO COM GASES OU VAPORES MUiTo Tóxicos dEVE USAR-SE FILTROS RESPIRATÓRIOS
Resistência a produtos químicos de materiais usados no fabrico de luvas *

Borracha
natural Neopreno Nitrilo Vinilo

Acetaldeido

Acetato de Etilo

Acetona

Ácido Acético

Ácido Bromídrico (40\%)

Ácido Cloridrico (conc)

Ácido Crómico

Ácido Fluorídrico (30\%)

Ácido Fórmico

Ácido Fosfórico

Ácido Nítrico (conc)

Ácido Perclórico

Ácido Sulfúrico (conc)

Acrilonitrilo

Anilina

Benzaldeído

Benzeno (a)

Bromo

Butano

Butiraldeido

Ciclo-hexano

Cloreto de Benzilo (a)

Cloreto de Metileno (a)

Cloreto de metilo (a)

Cloro

Cloroacetona

Cloroformio (a)

Dicloreto de Etileno (a)

Dicloreto de Propileno

(a)

Dietanolamina

Éter Dibenzilico

Éter Dietílico

Etileno Glicol

Flúor

Formaldeido

Ftalato Dibutilico

Glicerol

Hexano

Hidróxido Amónio (sat)

Hidróxido Potássio (sat)

Hidróxido de Sódio

Hipoclorito de Cálcio

Hipoclorito de Sódio

Iodo

Metilamina

Metil Celosolve

Metil Etil Cetona

Monoetanolamina

Morfolina

Naftaleno (a)

Peróxido de Hidrogénio

Sulfoxido Dimetílico (b)

Sulfureto de Carbono

Tetracloreto de Carbono

Tolueno (a)

Tricloreto de Etileno (a)

Tricloroetileno (a)

Trietanolamina

Trinitrotolueno

\begin{tabular}{|c|c|c|c|}
\hline B & B & $\mathrm{E}$ & B \\
\hline M & B & B & $\mathbf{M}$ \\
\hline B & B & B & M \\
\hline E & E & E & E \\
\hline B & E & - & E \\
\hline B & B & B & E \\
\hline$F$ & $\mathbf{M}$ & M & $\mathrm{E}$ \\
\hline B & B & B & E \\
\hline B & $\mathbf{E}$ & $\mathrm{E}$ & E \\
\hline B & E & - & E \\
\hline$F$ & $\mathbf{F}$ & $F$ & B \\
\hline M & B & $\mathbf{M}$ & E \\
\hline B & B & $\mathbf{M}$ & B \\
\hline F & B & - & M \\
\hline M & B & E & B \\
\hline $\mathbf{M}$ & $\mathbf{M}$ & E & B \\
\hline$F$ & M & B & $\mathbf{M}$ \\
\hline B & B & - & B \\
\hline$F$ & $\mathrm{E}$ & - & $\mathbf{F}$ \\
\hline F & B & - & B \\
\hline M & $\mathrm{E}$ & - & $\mathbf{F}$ \\
\hline $\mathbf{M}$ & $\mathbf{F}$ & B & $\mathbf{F}$ \\
\hline M & $\mathbf{M}$ & B & $\mathbf{M}$ \\
\hline$F$ & $\mathrm{E}$ & - & $\mathbf{F}$ \\
\hline B & B & - & B \\
\hline M & $\mathrm{E}$ & - & $F$ \\
\hline F & $\mathbf{M}$ & B & $\mathrm{F}$ \\
\hline $\mathbf{F}$ & $\mathbf{M}$ & B & $\mathrm{F}$ \\
\hline $\mathbf{F}$ & $\mathbf{M}$ & - & F \\
\hline $\mathbf{M}$ & $\mathbf{E}$ & - & $\mathrm{E}$ \\
\hline $\mathbf{M}$ & B & - & F \\
\hline $\mathbf{M}$ & B & $\mathrm{E}$ & $\mathrm{F}$ \\
\hline B & B & $\mathrm{E}$ & $\mathrm{E}$ \\
\hline B & B & - & B \\
\hline B & $\mathbf{E}$ & E & $\mathbf{E}$ \\
\hline M & B & - & $\mathbf{F}$ \\
\hline B & B & $\mathbf{E}$ & E \\
\hline $\mathbf{F}$ & E & - & $\mathbf{F}$ \\
\hline B & $\mathbf{E}$ & $\mathbf{E}$ & E \\
\hline B & B & B & $\mathrm{E}$ \\
\hline B & B & B & $\mathrm{E}$ \\
\hline$F$ & B & B & B \\
\hline B & $\mathrm{F}$ & $\mathbf{M}$ & B \\
\hline B & B & - & B \\
\hline B & B & E & $\mathrm{E}$ \\
\hline M & $\mathrm{E}$ & - & $\mathrm{F}$ \\
\hline $\mathbf{M}$ & B & B & $F$ \\
\hline M & $\mathrm{E}$ & - & E \\
\hline $\mathbf{M}$ & E & - & $\mathrm{E}$ \\
\hline B & B & E & B \\
\hline B & B & B & $\mathbf{E}$ \\
\hline- & - & - & - \\
\hline$F$ & $F$ & B & $\mathbf{M}$ \\
\hline $\mathbf{F}$ & $\mathbf{M}$ & B & $\mathbf{M}$ \\
\hline$F$ & $\mathbf{M}$ & B & $\mathbf{M}$ \\
\hline $\mathbf{F}$ & F & - & $F$ \\
\hline$F$ & $\mathbf{M}$ & B & $\mathbf{M}$ \\
\hline $\mathbf{M}$ & E & $\mathrm{E}$ & E \\
\hline$F$ & $\mathrm{E}$ & - & $\mathrm{F}$ \\
\hline
\end{tabular}

- $\mathbf{E}=$ excelente; $\mathbf{B}=$ boa; $\mathrm{M}=$ média; $\mathbf{F}=$ fraca

a) Os hidrocarbonetos aromáticos e halogenados atacam todos os tipos de borracha natural e sintética utilizados no fabrico de luvas. Se se observar alteraçð̄es nas luvas, devem ser postas a secar para que voltem ao normal e o utilizador deverá utilizar entretanto um novo par de luvas.

b) Não estão disponíveis dados sobre a resistência ao sulfóxido dimetílico pela borracha natural, neopreno, vinilo ou outros materiais sintéticos; o fabricante deste reagente recomenda o uso de luvas de borracha butilica.

Fonte: Prudent Practices for Handling Hazardous Chemicals in Laboratories, National Research Council, National Academy Press, Washington, D.C., 1981. 
exposição conhécidos e propriedades perigosas (por exemplo, irritante para os olhos ou absorvido pela pele).

Os filtros químicos destinados a ser utilizados com vapores ou gases actuam adsorvendo-os numa substância absorvente, em geral carvão activado. É extremamente importante conhecer a capacidade de cada filtro e tempo durante o qual foi utilizado, sendo recomendável que se substitua o filtro após cada utilização para assegurar o tempo máximo de utilização a cada operador. Este tipo de filtro químico não deve ser utilizado com vapores cujas propriedades não sejam bem conhecidas nem com aqueles que gerem calores de reacção elevados com o material adsorventes do filtro.

Os filtros destinados a ser utilizados na presença de poeiras, fumos e aerossóis actuam retendo as partículas numa rede de fibras e em geral são de deitar fora após cada utilização.

As máscaras respiratórias devem ser seleccionadas de modo a assegurar uma adaptação perfeita à face do utilizador, caso contrário pode haver penetração de contaminantes durante a sua utilização.

Para situaçðes de emergência e trabalhos de salvamento, é necessário dispôr de um máscara completa ligada a um cilindro de ar comprimido. A utilização destas máscaras exige treino prévio adequado. Por outro lado, sendo o suprimento de ar limitado ( 5 a 30 minutos), este tipo de equipamento não pode ser utilizado por períodos prolongados sem que o cilindro de ar seja substituído.

\section{5 - Protecção dos pés}

Em muitas circunstâncias pode ser necessária protecção superior à oferecida pelo calçado vulgar. Contudo, não são aceitáveis no laboratório os sapatos perfurados, os sapatos de lona ou as sandálias, pois não evitam a exposição dos pés a reagentes corrosivos e grandes quantidades de solventes ou de água (por exemplo, em operaçð̃es de limpeza), para além de serem perigosos junto de máquinas em movimento.

As botas de borracha e o calçado de plástico podem produzir descargas de electricidade estática, pelo que não se recomenda o seu uso em locais em que haja perigo de incêndio.

$\mathrm{O}$ uso de sapatos de segurança com solas antiderrapantes é recomendado para o laboratório, armazéns e oficinas e, em locais onde se movimente equipamento pesado, o calçado deverá ter biqueiras reforçadas.

Embora a conservação e manutenção em bom estado de funcionamento de todo o equipamento de protecção pessoal seja da responsabilidade de todos quantos trabalham no laboratório, é ao encarregado da segurança que cabe proceder à verificação periódica de todo esse equipamento e sua substituição sempre que necessário.

\section{Planeamento de Laboratório: uma breve listagem bibliográfica}

O planeamento, organização e gestão de laboratórios são factores fundamentais para assegurar condiçð̃es de segurança a todos os seus utentes. Por esse motivo se considera de extrema importância que todas as pessoas envolvidas na construção e/ou adaptação de edifícios a laboratórios, na selecção do mobiliário e outro equipamento tenham acesso a fontes de informação sobre essas matérias. Neste número do Boletim apresenta-se uma listagem bibiográfica sobre planeamento, organização e gestão de laboratórios. Em números subsequentes serão publicadas listagens sobre outros aspectos da segurança, nomeadamente selecção de extintores, armazenagem de reagentes, distruição de resíduos químicos, toxicologia.

- Nuffield Foundation, Division for Architectural Studies, The Design of Research Laboratories, Oxford University Press, 1961.

- Nunce, J.F., Laboratory Planning, Butterworths, London, 1962.

- Lewis, H.F. (Ed.), Laboratory Planning for Chemistry and Chemical Engineering, Reinhold Publishing Corp., New York, 1962.

- Schram, W. Chemistry and Biology Laboratories, Pergamon Press, London, 1965.

- Hughes, D. e Cullingworth, R., The Design of Laboratories for Radioactive and Other Toxic Substances, Koch-Light Laboratories Ltd, Colnbrook (UK), 1971.

- Ferguson, W.R., Practical Laboratory Planning, Applied Sciences Publishers, London, 1973. - Everett, K. e Hughes, D., Guide to Laboratory Design, Butterworths, London, 1975.

- Archenhold, W.F., Jenkins, E.W. e Wood-Robinson, C., School Science Laboratories: a Handbook of design, management and organization, John Murray, London, 1978.

- Grover, F. e Wallace, P., laboratory Organization and Management, Butterworths, London, 1979.

- Hughes, D., A Literature Survey and Design Study of Fumecupboards and Fume-Dispersal Systems, Occupational Hygiene Monograph No. 4, Science Reviews Ltd, 1980. 